\title{
PREVALENCE OF IMPAIRMENT IN PULMONARY FUNCTION TEST IN SUGAR DISTILLERY INDUSTRY WORKERS IN KARAD TALUKA
}

\author{
PRAJAKTA MAHADEO PAWAR ${ }^{1}$, SANDEEP BABASAHEB SHINDE ${ }^{2 *}$ \\ ${ }^{1}$ Department of Musculoskeletal Sciences, Faculty of Physiotherapy, KIMS “Deemed To Be University” Karad, Maharashtra, India. \\ ${ }^{2}$ Department of Musculoskeletal Sciences, Faculty of Physiotherapy, KIMS “Deemed to Be University” Karad, Maharashtra, India. \\ Email: drsandeepshinde24@gmail.com
}

Received: 03 October 2017, Revised and Accepted: 12 November 2018

ABSTRACT

Objective: The objective of this study was to find the prevalence of impairments in pulmonary function test (PFT) in sugar distillery industry workers in Karad taluka.

Methods: A total of 88 sugar distillery industry workers, both male and female with 5 years of the duration of exposure to sugar distillery industry in Karad taluka, were selected as per the inclusion criteria in this study. They were aged between 40 and 60 years. The outcome measures were PFT and 6 min walk test. Based on the outcome measures and conclusion were made.

Results: The study showed that among the 88 workers, 34 workers had normal pulmonary function, 25 of them had mild obstructive type of pulmonary impairments, 26 workers had mild restrictive type of pulmonary impairments, and remaining three workers had mixed type of lung disease for PFT.

Conclusion: The total $61.36 \%$ of workers were suffering from various impairments in PFT. The study concluded that statistically significant impairments in PFT are existed among workers of sugar distillery industry from Karad taluka.

Keywords: Pulmonary function test, Pulmonary impairments, 6 min walk test, Sugar industry workers.

(C) 2019 The Authors. Published by Innovare Academic Sciences Pvt Ltd. This is an open access article under the CC BY license (http://creativecommons. org/licenses/by/4. 0/) DOI: http://dx.doi.org/10.22159/ajpcr.2019.v12i2.30093

\section{INTRODUCTION}

Occupational health should aim at the promotion and maintenance of the highest degree of physical, mental, and social well-being of workers in all occupation; the protection of worker in their employment from risk resulting factors adverse to health; the placing and maintenance of worker; and occupation environment adapted to his physiological and psychological equipment and summarize the adaptation of work to man and of each to man his job. An industrial worker may be exposed to hazards depending on occupation; they are physical hazards, chemical hazards, biological hazards, mechanical hazards, and psychological hazards. Occupational diseases are the diseases arising out of or in the course of employment. Occupational diseases can be as dermatitis, cancer, pulmonary conditions, cardiac problems, and psychological origin [1].

Airway diseases are commonly encountered with people exposed to dust constantly, which over period of time may affect pulmonary functions. Lungs are affected due to any organic or inorganic dust to which workers are exposed. It is well known that the industrial dust inhalation over a long period leads to proliferative fibrotic changes in the lungs [2]. The signs and symptoms are cough, expectoration of sputum, hemoptysis, fever, dyspnea, wheeze, chest pain, hoarseness of voice, and loss of weight [3].

According to our regional findings, India is the largest consumer, with more than 450 sugar factories [4]. Maharashtra is one of the largest sugar producer states in India. Sugarcane processing involves many workers in sugar factory [5]. There are 236 sugar mills in the state having installed sugarcane crushing capacity of 0.73 million tons per day [6]. In Karad taluka along with sugar production of alcohol, ethanol, and spirit is also produced and supplied supplies to oil marketing companies. Sugarcane is a grass with high fiber bagasse, is the crushed stalk of sugarcane (Saccharum officinarum) after the sugar has been extracted.

Bagassosis is the health problem specified to this industry, which may result from bagasse exposure. Workers may be affected by chronic respiratory infections, which reduce their productivity and might include extrinsic allergic alveolitis and organic dust toxic syndrome [7]. Bagassosis is a respiratory disease caused by inhalation of bagasse dust, also called as farmer's lung [8]. The organic dust contains high concentrations of bioaerosols such as bacteria, actinomycetes, and fungi of plant and animal origin. The concentration and pathogenesis of this bioaerosol depend on source material, method of their storage technology of processing material, and their disposal [9]. One such organic dust is bagasse. Bagasse is a byproduct of sugarcane crushing, size range from 0.5 to $3 \mu$ is called as respirable dust, to which sugar factory workers are exposed by virtue of their occupation. Since 1970, very few pulmonary functions studies were reported in this field, until recently in 2008, a study by Patil from western Maharashtra reported decrease in forced vital capacity (FVC), forced expiratory volume in 1 second (FEV1), and peak expiratory flow rate (PEFR) in occupationally exposed groups to bagasse as compared to non-exposed group. However, this study was conducted during the operational period of a sugar factory [10].

They observed $40 \%$ of the symptomatic workers reported improvement in their symptoms when away from work. Hence, the present study is conducted on workers during the non-operational period of sugar factory [11]. Most commonly and easily affected are the lungs due to any organic or inorganic dust to which the workers are exposed. It is well known that the industrial dust inhalation over a long period leads to proliferative and fibrotic changes in the lungs. Talking to exposure to dust, it was found that the frequency of respiratory illness was greater among the exposed workers than non-exposed.

The cane sugar is not only utilized for the production of sugar but also the fiber which until recently went to a waste is now utilized in the manufacture of paper, cardboard, and rayon; therefore, bagassosis is also seen in all these industries also. Till now, many researchers have worked in the effect of different organic dusts on pulmonary function overlooking bagassosis as minor aliment [2]. 
Distillery workers may have various types of problem such as obstructive and restrictive problems. People with obstructive lungs disease have shortness exhaling all air from the lungs. Distillery workers are exposed to the toxic fumes of resulting from various processing methods. Due to damage to the air from the lungs or narrowing of the airways inside the lungs, exhaled air comes out more slowly than narrowing of the airways than normal. At the end of a full exhalation, an abnormally high amount of air may still linger in the lungs. It was observed that the workers deal with multiple health risk situations, predominantly to the risk of respiratory, musculoskeletal, and psychological problems and workrelated accidents due to work activities [12].

Repeated exposure to dusty environment in an industry causes airway disease which may affect pulmonary function over a period of time [2]. As the consequence of bagassosis, workers and their families experience serious impact on their quality of life in terms of costs of treatment and loss of income [6]. Hence, to find out the prevalence of impairment pulmonary function tests (PFTs) in sugar distillery industry workers in Karad taluka, this study was initiated.

\section{METHODS}

\section{Procedure}

After getting permission from protocol and ethical committee, permission was taken from governing bodies sugar distillery factories from Karad. The study was conducted in Krishna Hospital, Karad. The subjects fulfilling inclusion criteria were requested to participate in the study. The nature of the study was explained to the subjects and consent was taken. Detailed pulmonary assessment was carried out; data collected using the 6 min walk test (6 MWT) and PFT.

\section{Study design}

It was an analytical study.

\section{Subject criteria}

A total of 88 subjects, both male and female workers with more than 5 years of experience in sugar distillery industry, were selected in the study. They were aged between 40 and 60 years. The explanations about the study procedure were given. The outcome measures were $6 \mathrm{MWT}$ and PFT. The subjects who were not included in the study were known case of COPD, pulmonary tuberculosis, bronchial asthma, history of critical medical illness (chronic kidney disease, congestive heart failure, and stroke), and bedridden patients.

\section{Outcome measures}

The detailed history was taken from each subject before starting the study according to the items in the data sheet. After that, each subject was instructed about the 6 MWT and PFT assessment. The assessment was taken with the 6 MWT by the all measures such as systolic and diastolic blood pressure, pulse rate, fatigue, dyspnea, and SpO2 and was taken before and after the 6 MWT [13].

The PFT was done to see the level of FVC, FEV1, FEV1/FVC, PEFR, and forced expiratory flow $25-75 \%$. The anthropometric measurement (standing height, weight, etc.) was recorded. The whole procedure was explained to the subject and they were encouraged to practice this procedure before doing the PFT. The spirometric functions were recorded in the sitting position using an electronic computerized portable RMS spirometer. All the PFT were carried out at affixed time of the day, that is, $10 \mathrm{am}-12 \mathrm{pm}$. The room temperature was $34-36^{\circ} \mathrm{C}$ during the period of study. Spirometric studies were performed in distillery workers [2].

\section{RESULTS}

\section{MWT}

Table 1 shows that before and after 6 MWT, the mean of systolic blood pressure, diastolic blood pressure, pulse rate, fatigue, dyspnea, and SpO2 shows $\mathrm{p}$ value and $\mathrm{t}$ value and it is statistically significant.

\section{PFT}

The Table 2 shows the mean of and standard deviation of FVC, FEV1, FEV1/FVC, PEFR, FEF $25-75 \%$ and it shows $t$ value and $p$ value. It is extremely significant $(\mathrm{p}<0.0001)$. It has divided into various categories such as normal lung, obstructive lung disease, restrictive lung disease, and mixed type lung disease.

The Table 3 and Graph 1 shows the result of PFT. The result shows 34 workers are normal, 25 workers are obstructive, 26 workers are restrictive, and 3 workers are mixed.

\section{Statistical analysis}

The outcome measures were assessed at the baseline. The collected data in this study were statistically analyzed using descriptive statistics as mean, standard deviation, and percentage. The PFT and 6 MWT were analyzed paired t-test. $\mathrm{t}$ values were calculated in the 6 MWT and PFT. Statistical significance was accepted for the values of $p<0.05$ at $95 \%$ confidence interval. The total $61.36 \%$ of workers are suffering from various impairments in PFTs.

\section{DISCUSSION}

This project was done in 3 months with workers from sugar distillery industry with more than 5 years of experience and age group of 40-60 years was selected in the study. This research was undertaken with the aim to find out the prevalence of impairment in PFT in sugar distillery industry workers in Karad taluka. Sugar processing industry involves different suboccupations, which was performed in distinct

Table 1: Mean and standard deviation of 6 MWT

\begin{tabular}{lllll}
\hline 6 MWT & Before & After & t value & Result \\
\hline Systolic blood pressure & $127.73 \pm 6.108$ & $135.8 \pm 5.786$ & 18.724 & $<0.0001$ \\
Diastolic blood pressure & $84.205 \pm 4.347$ & $91.023 \pm 4.094$ & 15.109 & $<0.0001$ \\
Pulse rate & $73.63 \pm 1.655$ & $81.19 \pm 1.545$ & 79.191 & $<0.0001$ \\
Fatigue & 0 & $0.89 \pm 0.79$ & 11.671 & $<0.0001$ \\
Dyspnea & $0.18 \pm 0.38$ & $0.82 \pm 0.69$ & 11.550 & $<0.0001$ \\
Sp02 & $97.25 \pm 0.697$ & $98.53 \pm 0.501$ & 22.078 & Significant \\
\hline
\end{tabular}

6 MWT: 6 min walk test

Table 2: Mean and standard deviation of PFT

\begin{tabular}{llllll}
\hline Result: parameters of PFT & FVC & FEV1 & FEV1/FVC & PEFR & FEF 25-75\% \\
\hline Mean and standard deviation & $87.96 \pm 10.910$ & $83.67 \pm 12.77$ & $94.090 \pm 2.786$ & $72.30 \pm 10.840$ & $68.64 \pm 10.637$ \\
$t$ value & 75.638 & 63.889 & 75.638 & 62.574 & 62.574 \\
$p$ value & $<0.0001$ (ES) & $<0.0001$ (ES) & $<0.0001$ (ES) & $<0.0001$ (ES) & $<0.0001$ (ES) \\
\hline
\end{tabular}

FVC: Forced vital capacity, FEV1: Forced expiratory volume in 1 second, PEFR: Peak expiratory flow rate, PFT: Pulmonary function test, ES: Economic status 
Table 3: Result of PFT

\begin{tabular}{lllll}
\hline Result & Normal & Obstructive & Restrictive & Mixed \\
\hline PFT & 34 & 25 & 26 & 3 \\
\hline PFT: Pulmonary function test
\end{tabular}

\section{Prevalence of impairments in pulmonary function test}

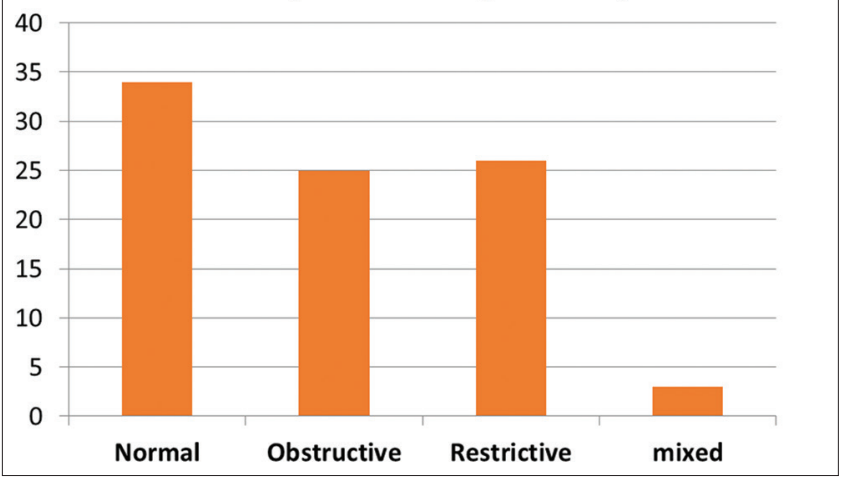

Graph 1: Results of pulmonary function test (PFT): Number of sugar distillery workers having impairments of PFT

processing units necessary in manufacturing of sugar. In view of current industrial health scenario in sugar factory, this is the first study with PFT conducted on workers in sugar distillery industry. Sugar distillery involves production of alcohol, ethanol, spirit, etc.

88 participants (83 males and 5 females) with age of 40-60 years participated in the study. An assessment was done. The assessment was taken with 6 MWT and PFT, statistical analysis was done using paired t-test.

The purpose of this study was to test the effectiveness of a $6 \mathrm{MW}$ as a measure of physical endurance in sizable sample of generally healthy, community-residing adult's age of 40-60 years. Specifically, the aim of the study to find out the strongest indication for 6 MWT is for measuring the response to medical interventions in patients with moderate-tosevere heart and lung disease. The 6 MWT has also been used as one time measures of functional status of patients, as well as predictor of morbidity and mortality. The fact that investigator has used the 6 MWT in these settings does not prove that chemically useful (best test) for determining functional capacity or changing functional capacity due to an intervention patient with this disease.

Formal cardiopulmonary exercise testing provides a global assessment of exercise response, an objective determination of functional capacity and impairment, determination of the appropriate intensity needed to perform prolonged exercise, quantification of factors limiting exercise, and definition of the underlying pathophysiologic mechanisms such as the contribution of different organ systems involved in exercise. The 6 MWT does not determine peak oxygen uptake, diagnose the cause of dyspnea on exertion, or evaluate the causes of mechanisms of exercise limitation $[14,15]$. The information provided by 6 MWT should be considered complimentary exercise testing, not a replacement for it.

In this study, the whole procedure was explained to subject and they were encouraged to practice this procedure before doing the PFT. The spirometric functions were recorded in the sitting position using an electronic computerized portable RMS spirometer. Each individual performs spirometry to produce best result, all PFTs were carried out at fixed time of the day, that is, $10 \mathrm{am}-12 \mathrm{pm}$. The room temperature was $34-36^{\circ} \mathrm{C}$ during the period of study. Spirometric studies were performed in distillery workers.
Distillery sugar factory workers suffered with various profile of obstructive (28.40\%), restrictive (29.54\%), and mixed type $(3.40 \%)$ of pulmonary impairments. 34 workers are having normal lung profile.

In this study, the PFT was extremely significant in sugar industry workers. In this study, 88 workers were involved. 83 were male and 5 were female. The result shows 34 workers are normal, 25 are having mild obstructive condition, 26 having mild restrictive condition, and three are having mild mixed type condition. Exposure of distillery industry may lead wide range of diseases ranging from lung cancer to allergic rhinitis.

In previously reported studies, all subgroups of sugar factory workers suffered with various profile of obstructive (18.03\%), restrictive $(11.56 \%)$, and mixed type $(2.38 \%)$ of pulmonary impairments totaling $31.97 \%$ versus $13.33 \%$ in controls. However, bronchial obstruction was the predominant pulmonary abnormality in suboccupational groups, especially bagasse workers (26.19\%) and manufacturing department workers (22.55\%) [2]. A spirometric study by Gehad Abo et al. [16] in workers chronically exposed to bagasse during the manufacture of particle boards showed the prevalence of obstructive ventilator defects in about $28.5 \%$ of the studied workers followed by restrictive defects affecting about $19.6 \%$ of the workers, while combined defect affected about $6 \%$ of studied group. The result in the present study may be due to the differential nature of occupational exposure.

There is an increasing number of cases in each obstructive, restrictive, and mixed type of pulmonary impairment from 11 to 20 years exposed worker category to $>31$ years exposed category, which means there is a direct correlation between the duration of exposure to dust and the pulmonary abnormalities in sugar factory workers. The other study can show that significant association between pulmonary function abnormalities and certain suboccupation in the sugar factory. The majority of workers with pulmonary impairment had $\geq 31$ years of occupational exposure. A direct correlation was observed between the duration of occupational exposure to the organic dust (bagasse) and increase in pulmonary impairment in sugar factory workers [2].

Sugar processing industries involve different suboccupation, which are performed in distinct processing unit necessary in the manufacturing of sugar. In view of the industrial health scenario the sugar factory, lung spirometric studies were conducted on workers in distillery department. There is evidence of cellular infiltration in the walls of respiratory bronchioles, leading to the formation of epithelioid granulomas [17]. Bronchiolar inflammation with its products and lymphocytes and granulomatous reactions may occlude the smallest airway [18]. Maximum voluntary ventilation is an effort dependent and, therefore, depends on strength of diaphragm and chest muscle, on the one hand, and pulmonary complaints and airway patency, on the other hand [19]. It provides an overall assessment of effort, coordination, and elastic and flow resistive properties of respiratory system. Consequently, it is necessary to implement health-care programs for this population, with the purpose of improving lung function and therefore improving the quality of life of obese individuals [20]. In the smokers, inflammation leads to permanent changes in the lung. The walls of the airways thicken and more mucus is produced. Damage to the walls of the air sacs in the lungs causes emphysema, and the lungs lose their normal elasticity [21].

Before the job recruitment in sugar distillery industry, it is must to perform medical health screening specifically for the cardiorespiratory system. After completion of work session, it is also recommended to perform medical health screening to keep regular health monitoring of these susceptible workers. These measures can help in prevention of respiratory impairments due to exposure in sugar distillery industry workplaces. Safety measures need to be followed by the workers are - wear helmets, safety shoes, mask and gloves, proper clothing, regular medical checkup, and proper diet and healthy lifestyle. Aerobic exercises are recommended for sugar industry distillery workers. It helps to improve their aerobic capacity and healthy respiratory habits. 


\section{CONCLUSION}

The total $61.36 \%$ of workers were suffering from various impairments in PFTs. The study concluded that statistically significant impairments in PFT are existed among workers of sugar distillery industry from Karad taluka.

\section{ACKNOWLEDGMENT}

We acknowledge the guidance and constant support of Dr. Varadharajulu G, Dean, Faculty of Physiotherapy, Karad, Dr. Sandeep Shinde, and Dr. Kakade SV for help in statistical analysis.

\section{AUTHORS' CONTRIBUTION}

Prajkata M. Pawar conducted literature review for this manuscript, developed introduction section of the manuscript together with the discussion of the study findings, collected data, and analyzed the data. Dr. Sandeep B. Shinde provided a description of the background information, collected data and analyzed the data, and participated in preparation of the manuscript. All the authors read and approved the final manuscript.

\section{CONFLICTS OF INTEREST}

The authors declare that there are no conflicts of interest concerning the content of the present study.

\section{REFERENCES}

1. Park K. Park's Textbook of Prevention and Social Medicine. $23^{\text {rd }}$ ed. Jabalpur, India: Banarasidas Bhanot Publishers; 2014. p. 803-7.

2. Nene SB, Shete SS. Dynamic lung profile in sugarcane industry workers. Int J Basic Med Sci 2017;7:976-3554.

3. Munjal YP. API Textbook of Medicine. $10^{\text {th }}$ ed. New Delhi, India: Jaypee Brothers Medical Publishers (P) Ltd.; 2015. p. 1130-40.

4. Alan P, Nicholson D. Pulmonary function in bagasse workers lung disease. Am Rev Respir Dis U S A 1968;97:561-70.

5. Jenkins DE, Suresh K. Mallik: Sequence observations on pulmonary functions department in bagassosis. Arch Inter Med 1971;128:535-40.

6. Deshmukh S. 41 $1^{\text {st }}$ Annual Report Vasantdada Sugar Institute. Manjari BK, District Pune, Maharashtra, India; 2016-17. p. 29.
7. Sakunkoo P, Chaiear N, Chaikittiporn C, Sadhra S. Concentrations and size distribution of inhalable and respirable dust among sugar industry workers: A pilot study in Khon Kaen, Thailand. Asia Pac J Public Health 2011;23:967-79.

8. Marinenko NV, Metliaev GN. Bagassosis, an occupational disease of the lungs (a review of the foreign literature). Gig Tr Prof Zabol 1979;5:39-41.

9. Ata GA, Ezzat HM, Shalaby AO, Kholey BE. Environmental mycological and respiratory health assessment of workers chronically exposed to bagasse in Egyptian particle board industry. Int J Environ Health Res 1998;8:315-34

10. Viswanathan R, De Monte AJ, Shivpuri DN, Venkitasubramoni JA. Bagassossis: A study of pulmonary function. Ind $\mathrm{J}$ Med Res 1963;51:563-693.

11. Nikhade NS, Sharma P. A study of pulmonary function test in workers of sugar factory, Pravaranagar, Maharashtra. Int J Med Res Health Sci 2013;2:52-8

12. Cornland DW, Yamba F. Text Book of Sugarcane Resources for Sustainable Development: A Case Study in Luena, Zambia. Sweden: Stockholm Environment Institute; 2001. p. 27-8.

13. Rocha FL, Marziale MH, Hong OS. Work and health conditions of sugar cane workers in Brazil. Rev Esc Enferm USP 2010;44:974-9.

14. Gehad A. Environmental, mycological and respiratory health assessment of workers chronically exposed to bagasse in Egyptian particle-board industry. Health Res 1998;8:315-34.

15. Weisman IM, Zeballos RJ. An integrated approach to the interpretation of cardiopulmonary exercise testing. Clin Chest Med 1994; $15: 421-45$

16. Enright PL. American thoracic society, guidelines for 6 minute walk test. Am J Respir Crit Care Med 2002;166:111-7.

17. Kurup VP. Faemers lung and related hypersensitivity pneumonitis. Indian J Chest Dis All Sci 1984;26:142-255.

18. Seaton A. Croton and Douglas's Respiratory Disease. $5^{\text {th }}$ ed., Vol. 2. Chichester: Wiley; 2000. p. 1002

19. Singh V, Pande JN, Khilnani GC. Tests for ventilator function. In: Shankar S, editor. Pulmonary Function Tests in Health and Diseases. $1^{\text {st }}$ ed. Mumbai: Indian College of Physicians; 1998. p. 39, 46-59.

20. Bhattacharjee A, Thygoo AA, Rammohan S. Impact of obesity on pulmonary functions among young non-smoker healthy female of Shah Alam, Malaysia. Asian J Pharm Clin Res 2018;11:465-9.

21. Manikandan S, Anandhalakshmi S, Nageswari AD. Comparison of the effects of various modes of smoking on the pulmonary functions in healthy volunteers. Asian J Pharm Clin Res 2015;8:289-91. 